\title{
Reaction class-based frameworks for heterogeneous catalytic systems
}

\author{
P. Kraus ${ }^{\mathrm{a}}$, R. P. Lindstedt ${ }^{\mathrm{a}, *}$ \\ ${ }^{a}$ Department of Mechanical Engineering, Imperial College London, South Kensington Campus, London, \\ $S W 7$ 2BX, UK
}

\begin{abstract}
A systematic and self-consistent approach is applied to study the combustion of hydrogen and syngas over platinum using coupled detailed gas phase and surface reaction mechanisms. The surface chemistry is derived using a reaction class-based framework comprising variational transition state theory (VTST), two-dimensional collision theory and the unity bond index - quadratic exponential potential for barrier heights. The latter approach is augmented by the inclusion of more accurate data, such as the heat of adsorption of CO, and VTST is used to systematically remove the need for the surface sticking coefficients associated with adsorption and desorption processes. Transition-state theory estimates for several reaction classes are produced by combining the M06 family of density functionals with the Stuttgart/Dresden effective core potential for metal atoms. The developed method reproduces experimental data with an accuracy comparable or better than the previously used collision theory approach and without the reliance on experimental parameters. The presented framework is well-suited for the efficient generation of novel heterogeneous reaction mechanisms and also serves to identify key parameters where high accuracy ab initio methods may be required. The latter is exemplified via the sensitivity of selected results to the adsorption of carbon monoxide on platinum.
\end{abstract}

Keywords: Fuel reformation, Partial oxidation, Surface chemistry, Catalytic combustion

*Corresponding author. Fax: +44 2075893905

Email address: p.lindstedt@imperial.ac.uk (R. P. Lindstedt)

Preprint submitted to Proceedings of the Combustion Institute 36

May 26, 2016 


\section{Introduction}

Most current microkinetic models for heterogenous systems rely on the extended threeparameter Arrhenius form to describe reaction rates [1-3]. The activation energy $\left(E_{A}\right)$ is the most studied parameter, with a range of estimation methods of varying accuracy available. Vlachos et al. $[4,5]$ have shown that periodic Density Functional Theory (DFT) can be applied to modelling of ethylene reactivity on platinum (Pt), while Raybaud et al. [6] have reviewed DFT modelling of supported Pt catalysts. By comparison, the pre-exponential terms $(A(T))$ are poorly studied as $E_{A}$ often exerts a dominant influence. In adsorption processes, $A(T)$ is generally calculated from experimentally-derived sticking coefficients [4, 7]. However, even for well studied reactions, the published values can vary by an order of magnitude - the reported values for $\mathrm{H}_{2}$ on $\mathrm{Pt}(111)$ are in the range of 0.005 and 0.1 [8], with 0.06 being the most recent value [9]. Where sticking coefficients are unavailable, the preexponential terms are typically adjusted heuristically to fit experimental data [10] should such be available. For homogeneous surface reactions, approaches vary from estimates [10] and $2 \mathrm{D}$ collision theory [7] to transition-state theory (TST) calculations where DFT results are available [4]. However, the contribution of vibrational partition functions was omitted in recent studies $[11,12]$.

The widely-used $\mathrm{CH}_{4} / \mathrm{O}_{2} / \mathrm{Pt}$ mechanism by Deutschmann et al. [13], based on work by Warnatz et al. [8] and Hellsing et al. [14], uses rate parameters derived from fitting to experimental data. The mechanism produces excellent results on Pt. However, such approaches are more difficult to apply to less studied metals. A reaction class-based framework has been proposed by Vincent et al. [7] in order to increase generality. However, adsorption processes are still treated using sticking coefficients with key reaction rates adjusted based on a sensitivity analysis. Recently, a revised systematic framework has been proposed $[15,16]$ that combines an unity bond index - quadratic exponential potential (UBI-QEP) method for barrier estimation [17] with 2D collision theory for homogeneous surface pre-exponentials [7] and TST for adsorption and desorption processes. The approach eliminates all dependencies on experimental parameters and more accurate rate [18] or barrier height determinations [19] 
Table 1: Experimental conditions for hydrogen combustion studies in lean [33], preheated lean [34] and rich [35] cases: reactor length $\mathrm{L}$, equivalence ratio $\phi, \mathrm{N}_{2} / \mathrm{O}_{2}$ molar ratio, superficial inlet velocity $\mathrm{U}_{\text {in }}$, temperature of inlet gas $\mathrm{T}_{i n}$, temperature of the catalytic wall at inlet $\mathrm{T}_{i n}^{W}$, pressure $\mathrm{P}$.

\begin{tabular}{rrrrrrrr}
\hline Case & $\begin{array}{c}\mathbf{L} \\
{[\mathrm{mm}]}\end{array}$ & $\phi$ & $\frac{\mathbf{N}_{2}}{\mathbf{O}_{2}}$ & $\begin{array}{c}\mathbf{U}_{i n} \\
{[\mathrm{~m} / \mathrm{s}]}\end{array}$ & $\begin{array}{c}\mathbf{T}_{i n} \\
{[\mathrm{~K}]}\end{array}$ & $\begin{array}{c}\mathbf{T}_{i n}^{W} \\
{[\mathrm{~K}]}\end{array}$ & $\begin{array}{c}\mathbf{P} \\
{[\mathrm{bar}]}\end{array}$ \\
\hline $\mathbf{L 0 1}$ & 200 & 0.28 & 3.71 & 3.00 & 310 & 1136 & 1 \\
$\mathbf{L 0 4}$ & 200 & 0.28 & 3.71 & 0.75 & 310 & 1112 & 4 \\
$\mathbf{L 0 5}$ & 200 & 0.28 & 3.71 & 0.50 & 310 & 1109 & 6 \\
\hline $\mathbf{P 0 7}$ & 300 & 0.11 & 3.77 & 6.50 & 653 & 1011 & 2 \\
$\mathbf{P 2 1}$ & 300 & 0.11 & 4.07 & 1.38 & 671 & 1011 & 12 \\
\hline $\mathbf{R 0 8}$ & 300 & 3.50 & 8.93 & 1.30 & 311 & 900 & 3 \\
$\mathbf{R 1 0}$ & 300 & 6.50 & 5.13 & 1.00 & 312 & 808 & 5 \\
\hline
\end{tabular}

Table 2: Experimental conditions for syngas combustion studies in lean $(\phi=0.33)[36]$, $\mathrm{CO}_{2}$ diluted $(\phi=0.20)[37]$ and rich $\left(\phi=2\right.$ and 7) [38] cases: inlet composition (balance is $\left.\mathrm{N}_{2}\right)$, superficial inlet velocity $\mathrm{U}_{i n}$, temperature of inlet gas $\mathrm{T}_{i n}$, temperature of the catalytic wall at inlet $\mathrm{T}_{i n}^{W}$, pressure $\mathrm{P}$.

\begin{tabular}{|c|c|c|c|c|c|c|c|c|}
\hline Case & $\mathrm{CO}$ & $\mathbf{H}_{2}$ & & $\mathrm{CO}_{2}$ & $\begin{array}{c}\mathbf{U}_{i n} \\
{[\mathrm{~m} / \mathrm{s}]}\end{array}$ & $\begin{array}{l}\mathbf{T}_{i n} \\
{[\mathrm{~K}]}\end{array}$ & $\begin{array}{c}\mathbf{T}_{i n}^{W} \\
{[\mathrm{~K}]}\end{array}$ & $\begin{array}{c}\mathbf{P} \\
{[\mathrm{bar}]}\end{array}$ \\
\hline L08 & 7.8 & 3.9 & 17.7 & - & 1.1 & 426 & 1150 & 5 \\
\hline D04 & 1.2 & 4.7 & 14.8 & 15.1 & 3.0 & 558 & 1088 & 4 \\
\hline D14 & 4.5 & 2.3 & 16.8 & 11.4 & 1.4 & 651 & 1059 & 12 \\
\hline R03 & 16.6 & 8.3 & 6.1 & - & 0.7 & 339 & $\sim 1009$ & 5 \\
\hline R13 & 12.5 & 62.3 & 5.3 & - & 0.9 & 336 & 897 & 7 \\
\hline
\end{tabular}

can be introduced seamlessly. This work is here extended by: (i) a systematic application of variational transition state theory (VTST) for determination of adsorption and desorption pre-exponentials, (ii) an updated collision theory approach for homogeneous surface reactions, (iii) the formulation of a self-consistent reaction mechanism and (iv) validation against a wide range of experimental data.

\section{Experimental data}

The $\mathrm{H}_{2} / \mathrm{O}_{2} / \mathrm{Pt}$ system has been investigated both experimentally and theoretically in the past, including high temperature desorption [20], catalytic ignition on $\mathrm{Pt}$ wires [21] and studies of stagnation point flames [22, 23]. Apart from being an important building block for all surface mechanisms on Pt, practical applications include energy generation in catalytic micro-reactors [24]. The recent growth of interest in syngas is tied to advances in biofuels and gasification. Recent work [25-27] includes the reforming of glycerol on Pt 


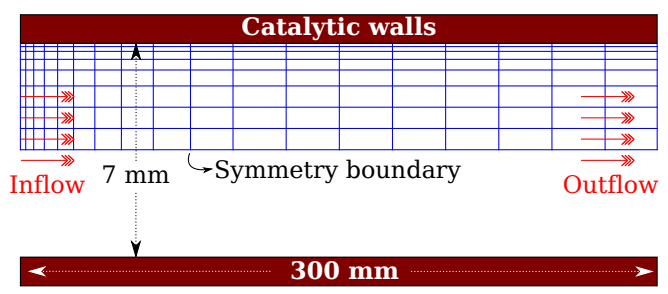

Figure 1: A diagram of the computational domain overlaid over the outline of the experimental configuration.

catalysts leading to hydrogen-rich syngas. Similarly, partial catalytic oxidation of methane is presently an important area of research [28, 31, 32].

Mantzaras and co-workers investigated $\mathrm{H}_{2} / \mathrm{O}_{2} / \mathrm{N}_{2}$ mixtures under various conditions: lean mixtures at atmospheric and high pressures [33], with various preheats [34] and under fuel rich conditions [35]. Similarly, combustion of syngas has been investigated at high pressure in lean [36], $\mathrm{CO}_{2}$ diluted [37] and rich [38] conditions. The datasets were obtained in a consistent experimental configuration and have been chosen for validation of the present mechanism. The experimental conditions are presented in Tables 1 and 2 .

\section{Computational methods}

The experimental reactor is duct-shaped, with the top and bottom wall catalytically active and the side walls inert [33-35]. A purpose-written, 2D parabolic ForTRAn code [7, 39] has been used to model the computational domain, simulated as a $3.5 \times 300 \mathrm{~mm}$ section corresponding to the top half of the duct bounded by a catalytic wall, as presented in Fig. 1. The computations were performed using a locally refined grid of 60 cells in the vertical direction, resulting in a resolution of $9 \mu \mathrm{m}$ close to the surface, and a maximum axial step of $1 \mu \mathrm{m}$. The platinum surface site density $(\Gamma)$ was set to $2.7 \times 10^{-5} \mathrm{~mol} / \mathrm{m}^{2}$ [33]. The temperature at the catalytic wall was imposed using experimental data, apart from case R03, where the imposed profile was approximated using data from related cases.

\section{Gas-phase chemistry}

A previously-applied $\mathrm{C}_{1}-\mathrm{C}_{2}$ mechanism was used to maintain consistency with the work of Vincent et al. [7]. Comparisons with gas-phase ignition results obtained with (i) the mech- 
anism of Li et al. [40], used by Mantzaras et al. [33-35], and (ii) a more recent mechanism of Burke et al. [41] are also included below.

\section{Surface chemistry}

The surface chemistry features 35 adsorbed species and 284 reversible reactions, with the $\mathrm{H}_{2} / \mathrm{O}_{2}$ submechanism consisting of 9 species and 43 reversible reactions. The mechanism was obtained using a revised systematic approach, based on the framework of Kraus and Lindstedt $[15,16]$, applied to the reaction classes in Table 3.

\subsection{Calculation of reaction activation energies}

The class-based methodology [7] based on the UBI-QEP method [17] forms the current starting point. The method allows for systematic calculation of reaction barriers, based on the heats of adsorption of reactants onto the catalyst $\left(\mathrm{Q}_{R}\right)$ and the total bond energies of the reacting species. The majority of the $\mathrm{Q}_{R}$ values were obtained by direct application of UBIQEP. However, in accordance with the UBI-QEP framework, $\mathrm{Q}_{R}$ for $\mathrm{OH}, \mathrm{CH}_{4}$ and $\mathrm{CO}$ were substituted by values from experimental studies, as implemented by Vincent et al. [7, 19]. Energetics of Pt-CO bonding have been previously highlighted as a sensitive parameter [7], arugably beyond the applicability of the UBI-QEP method [17].

\subsection{Calculation of Arrhenius pre-exponential factors}

The 2D collision theory-based method presented by Vincent et al. [7] was used for homogeneous surface reactions. Adsorption and desorption processes are treated via the application of (variational) TST as described by Dumesic et al. [42]. The definition of reaction classes is consistent with previous work [7] with current formulas listed in Table 3. All pre-exponential factors are further multiplied by $\Gamma^{1-m}$, where $m$ indicates the total number of reactants and additional $\mathrm{Pt}$ sites involved in the reaction.

\subsection{Calculation of partition functions}

Partition functions for the gas-phase and adsorbed species are required for establishing the current pre-exponential factors for adsorption and desorption processes. Based on the 
Table 3: Formulas for determination of pre-exponential factors for all considered reaction classes [7, 42]. Where $k_{B}, R$ and $h$ are the Boltzmann, universal gas and Planck constants respectively, $A_{X}$ and $r_{X}$ are the projected surface area and collision radius of $X$ respectively. Values of $A_{X}$ and $r_{X}$ have been re-calculated using Steric [43] and are available in

\begin{tabular}{l|l}
\multicolumn{2}{c}{ the supplementary material. } \\
\hline Reaction class & Formula: $A(T)=$ \\
$\begin{array}{l}\text { Direct adsorption } \\
\text { Dissociation }\end{array}$ & $\frac{1}{m^{m}} \frac{k_{B} T}{h} \frac{Q_{A \ddagger}^{\prime \prime}}{Q_{A g}^{\prime \prime \prime}}$ \\
\hline Eley-Rideal & $\frac{1}{m^{m}} \frac{k_{B} T}{h} \frac{Q_{A \ddagger}^{\prime \prime}}{Q_{A g}^{\prime \prime \prime}} \frac{A_{B s}}{A_{P t}}$ \\
\hline Direct desorption & $\frac{k_{B} T}{h} \frac{Q_{A \ddagger}^{\prime \prime}}{Q_{A s}^{\prime \prime}}$ \\
\hline $\begin{array}{l}\text { Recombination } \\
\text { Bimolecular surface } \\
\text { Unimolecular with catalyst }\end{array}$ & $\frac{1}{3 m^{m}} \frac{2\left(r_{A}+r_{B}\right)}{A_{P t}} \sqrt{\frac{\pi R T}{2 M_{R}}}$ \\
\hline \begin{tabular}{l} 
Unimolecular \\
\hline
\end{tabular} & $\frac{1}{m^{m}} \frac{k_{B} T}{h}$ \\
\hline
\end{tabular}

principle of microscopic reversibility, the adsorption transition state (TS, $\ddagger$ ) will be the same as the desorption TS, requiring a single additional partition function. The overall partition function of species $X$ is defined as $Q_{X}^{n^{\prime}}=q_{T}^{n^{\prime}} q_{V} q_{R} q_{E}$, where $q_{T}^{n^{\prime}}$ is the n-dimensional translational, $q_{V}$ the vibrational, $q_{R}$ the rotational and $q_{E}$ the electronic partition function. Excited states in the electronic partition function are generally very high in energy and $q_{E} \sim 1$. The translational, rotational and vibrational partition functions are calculated using established formulas [42]. For the vibrational partition function, the first energy level was chosen as the point of zero energy [44], and the effect of $q_{V}$ on the pre-exponential factor is systematically included. Gaussian 09 [45] was used to obtain the moments of inertia and the vibrational frequencies for each species using the following methods:

- Parameters for the gas-phase partition functions were calculated using the M06-2X density functional [46] and the 6-31G(2df,p) basis set after initial optimisation at the same level of theory.

- Adsorbed species and transition states were modelled as attached to $x$ Pt atoms as required by their surface coordination. The exchange contribution in M06-2X made convergence difficult and therefore the M06 density functional [46] was used. 


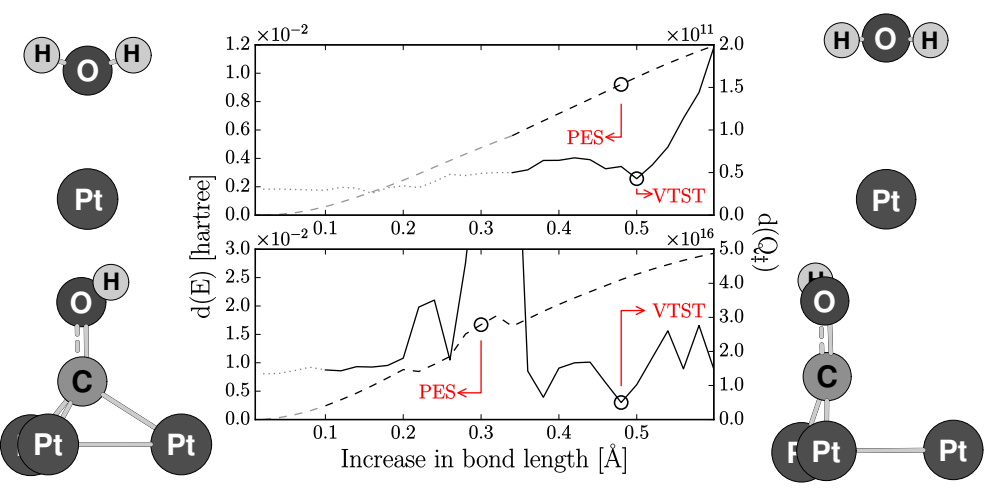

Figure 2: Transition state determination using canonical variational criterion $(-)$ and the PES-shape method (- -) for $\mathrm{H}_{2} \mathrm{O}$ and $\mathrm{COH}$ adsorption. Shaded lines indicate lack of an imaginary frequency. Structures on the left correspond to the adsorbed state, structures on the right correspond to a $0.6 \AA$ increase in bond length.

A mixed basis set consisting of $6-311 \mathrm{G}(\mathrm{d}, \mathrm{p})$ for carbon, oxygen and hydrogen and the Stuttgart/Dresden effective core potential [47] for Pt was used. A vibrational frequency analysis followed optimisation at the same level of theory.

- The TS structure was estimated based on a relaxed potential energy surface (PES) scan along the predicted direction of desorption using $0.02 \AA$ spacing of the adjusted coordinate, starting from the adsorbed species. In previous work [15], the TS was chosen based on the shape of the PES, which posed issues for barrierless adsorptions. Here, the position of the TS was determined variationally by minimizing the desorption rate using the canonical variational criterion method [48], given in Eq. (1),

$$
\frac{\delta k^{\infty}}{\delta r^{f}}=\frac{\delta Q_{A \ddagger}^{\prime \prime}}{\delta r^{f}}=0
$$

where $\delta r^{f}$ is an increase in forward reaction coordinate, $Q_{A \ddagger}^{\prime \prime}$ the overall partition function of the TS, and $k^{\infty}$ the high-pressure temperature dependent rate constant. Canonical VTST provides an improvement over conventional TST [29], especially for barrierless processes [30], and as such is implemented into a number of state-of-the art computational tools (e.g. Polyrate [49]). The two approaches are compared as a function of increase in breaking bond length in Fig. 2. The final TS structure contains a single imaginary frequency in the direction of the breaking bond. 


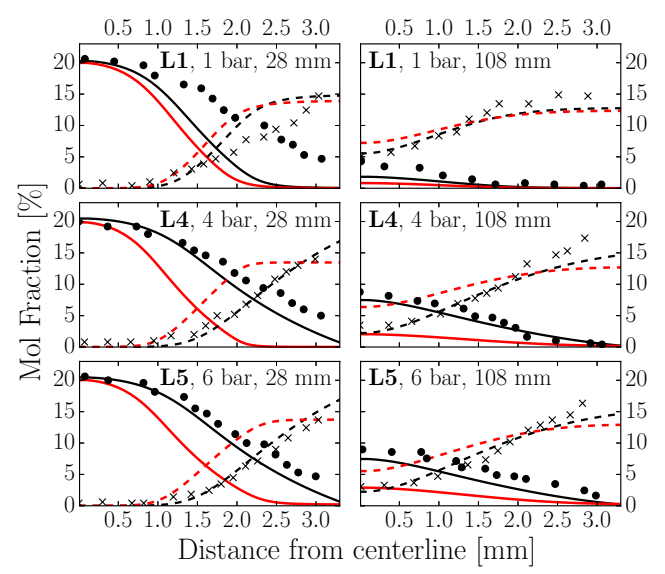

Figure 3: Experimental (symbols) and computational (lines) mol fraction profiles for $\mathrm{H}_{2}(\bullet,-)$ ) and $\mathrm{H}_{2} \mathrm{O}$ $(\times,--)$ at two axial locations for lean (L1, L4, L5) hydrogen combustion [33]. Simulations with gas and surface chemistry $(-)$, and with gas phase chemistry only $(-)$.

The M06 and M06-2X functionals were selected on the basis of good performance when compared to reference coupled cluster methods at the CCSD(T)/jun-cc-pVTZ//M06-2X/6$311++\mathrm{G}(3 \mathrm{df}, 3 \mathrm{pd})$ level for comparatively complex molecules [50]. The chosen basis sets contain polarisation corrections, while not being prohibitively large. Corrections for hindered rotors were obtained using the Pitzer-Gwinn method [51] as implemented in Gaussian 09 [45] as more direct estimates of the rotational barrier involve increased computational effort and complexity. Selected reaction rates are presented in Table 4, with the full mechanism available as supplementary material.

\section{Results and Discussion}

\subsection{Hydrogen combustion}

The experimental data and calculated results for the lean hydrogen/air cases L1, L4 and L5 are presented in Fig. 3. Calculations including surface chemistry (-) show agreement within $2 \mathrm{~mol} \%$ of the experimental data for both $\mathrm{H}_{2}$ consumption and $\mathrm{H}_{2} \mathrm{O}$ production in the high-pressure cases L4 and L5. At atmospheric pressure, the inlet mixture of case L1 is predicted to ignite early. The gas-phase ignition occurs at an axial distance consistent with the ignition delay of the mixture. In agreement with Mantzaras et al. [33], inclusion of surface chemistry has an inhibiting effect on hydrogen conversion (cf. (-)). 


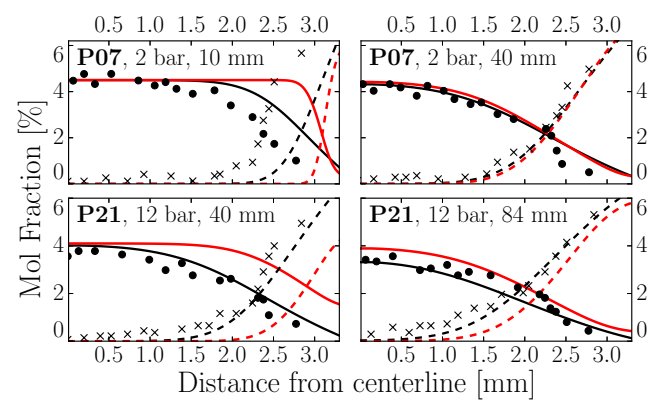

Figure 4: Experimental and computational mol fraction profiles at two axial locations for the lean preheated (P07, P21) hydrogen combustion [34]. Symbols and lines as in Fig. 3.

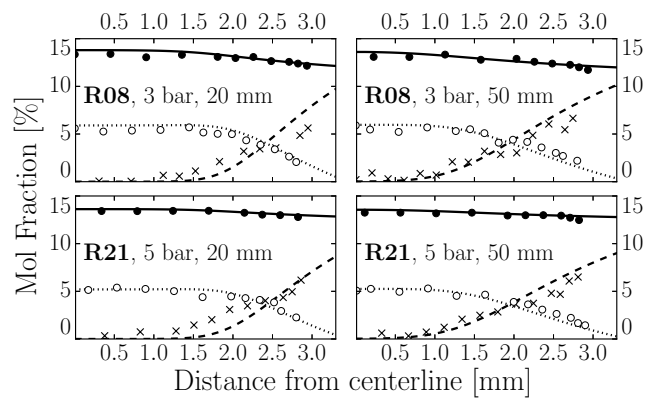

Figure 5: Experimental (symbols) and computational (lines) mol fraction profiles for $\mathrm{H}_{2}(\bullet,-), \mathrm{H}_{2} \mathrm{O}(\times,--)$ and $\mathrm{O}_{2}(0, \cdots)$ at two axial locations for the rich hydrogen combustion cases R08 and R10 [35]. All $\mathrm{H}_{2}$ data is scaled down by a factor of 3 and 5 for cases R08 and R10 respectively. Simulations carried out with gas and surface chemistry.

Figure 4 shows comparisons for preheated cases P07 and P21. There is close agreement, within $1 \mathrm{~mol} \%$ beyond $40 \mathrm{~mm}$ downstream. The $10 \mathrm{~mm}$ downstream location for case P07 shows slight under-prediction in $\mathrm{H}_{2}$ conversion. The mixture is very lean $(\phi=0.11)$ and closer to the flammability limit and the positive catalytic effect of surface chemistry is now clearly pronounced. The contribution of the catalytic chemistry is important especially in the first $50 \mathrm{~mm}$ of the reactor. The behaviour of the $\mathrm{H}_{2} / \mathrm{O}_{2} / \mathrm{N}_{2} / \mathrm{Pt}$ system under fuelrich conditions was investigated for cases R08 and R10. Results at two axial locations are presented in Fig. 5. The calculated conversion of both reactants and the major product shows agreement with the experimental data within $0.5 \mathrm{~mol} \%$ and $2 \mathrm{~mol} \%$ respectively, at all three axial locations. The combustion process is completely dependent on surface chemistry, as simulations without catalytic chemistry show no conversion.

Site coverages of selected species along the reactor are shown in Fig. 6. Under lean 
Table 4: Selected reaction rate constants.

\begin{tabular}{c|l|l}
\hline \multicolumn{3}{|c}{ Units are $\mathrm{m}, \mathrm{s}$ and $\mathrm{kJ} / \mathrm{mol}}$. \\
\hline \# & Reaction & Rate constant: $k=$ \\
\hline $\mathrm{R} 1$ & $\mathrm{H}_{2}+\mathrm{O}(s)+\mathrm{Pt}(s) \rightarrow \mathrm{H}(s)+\mathrm{OH}(s)$ & $9.21 \times 10^{6} \times T$ \\
$\mathrm{R} 2$ & $2 \mathrm{OH}(s) \rightarrow \mathrm{O}(s)+\mathrm{Pt}(s)+\mathrm{H}_{2} \mathrm{O}$ & $1.53 \times 10^{11} \times T^{0.5} \mathrm{e}^{-77.15 / R T}$ \\
$\mathrm{R} 3$ & $\mathrm{H}(s)+\mathrm{OH}(s) \rightarrow \mathrm{H}_{2} \mathrm{O}(s)+\mathrm{Pt}(s)$ & $3.77 \times 10^{11} \times T^{0.5} \mathrm{e}^{-46.61 / R T}$ \\
\hline $\mathrm{R} 4$ & $\mathrm{CO}+2 \mathrm{Pt}(s) \rightarrow \mathrm{CO}(s)_{2}$ & $2.08 \times 10^{4} \times T$ \\
$\mathrm{R} 5$ & $\mathrm{CO}_{2}+2 \mathrm{Pt}(s) \rightarrow \mathrm{CO}_{2}(s)_{2}$ & $2.58 \times 10^{6} \times T$ \\
\hline $\mathrm{R} 6$ & $\mathrm{O}_{2}+2 \mathrm{Pt}(s) \rightarrow 2 \mathrm{O}(s)$ & $1.92 \times 10^{1} \times T^{0.5}$ \\
$\mathrm{R} 7$ & $\mathrm{O}+\mathrm{Pt}(s) \rightarrow \mathrm{O}(s)$ & $2.64 \times 10^{1} \times T^{1.5}$ \\
\hline
\end{tabular}

conditions, $>70 \%$ of surface sites are covered by $\mathrm{O}(\mathrm{s})$. The surface chemistry proceeds mainly via an Eley-Rideal reaction of $\mathrm{H}_{2}$ with $\mathrm{O}(s)$, forming a dominant two-step pathway from $\mathrm{H}_{2}$ to $\mathrm{H}_{2} \mathrm{O}\left(\mathrm{R} 1 / \mathrm{R} 2\right.$ in Table 4). Under rich conditions, dissociative adsorption of $\mathrm{H}_{2}$ becomes more important, with any $\mathrm{O}(s)$ rapidly hydrogenated to $\mathrm{H}_{2} \mathrm{O}$ by excess $\mathrm{H}(s)$ ( R3 in Table 4). Most of the surface remains free of adsorbates. Upon depletion of gas-phase oxygen, the coverage of hydrogen slightly increases, but remains well below $0.1 \%$.

\subsection{Hydrogen gas phase ignition}

Homogeneous ignition distances for rich cases are presented in Fig. 7. The ignition distance does not correlate with pressure under rich conditions, possibly due to variations in $\mathrm{N}_{2}$ dilution and inlet temperature. All three gas phase mechanisms lead to under-prediction of the ignition distance, with the mechanism of Burke et al. [41] showing the largest deviation. Calculations show faster ignition also under lean conditions. Again, the mechanisms of Vincent et al. [19] and Li et al. [40] are consistent, while the mechanism of Burke et al. [41] predicts a shorter ignition distance. Parabolic calculations may yield longer ignition distances when compared to elliptical simulations [52]. The mechanism of Li et al. [40] was used by Mantzaras et al. [33-35], and was found to predict ignition distances within $10 \mathrm{~mm}$ of the experiments [34]. Hence, the under-prediction may be caused by modest differences in boundary conditions.

\subsection{Syngas combustion}

Experimental data and computational results for fuel lean combustion of syngas are presented in Fig. 8. Predicted species profiles of reactants and major products are within 


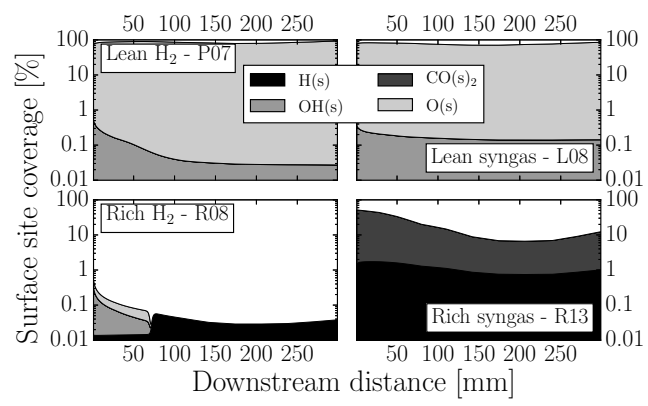

Figure 6: Stacked plot of site coverage of selected surface species at the catalytic wall in $\mathrm{H}_{2}$ and syngas combustion under fuel lean and rich conditions.

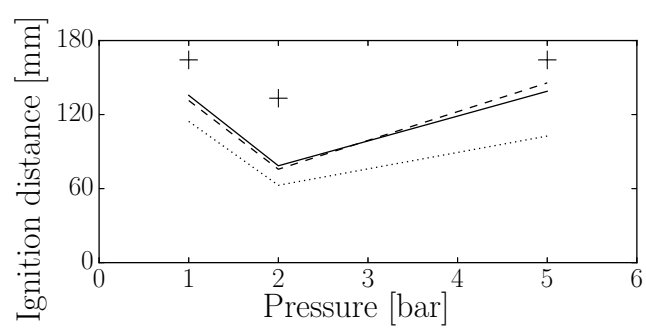

Figure 7: Homogeneous ignition distances for hydrogen combustion at $\phi=4.0$ [35]. Symbols $(+)$ represent experimental data, lines represent computational results obtained with surface chemistry and with the original gas-phase mechanism (-), mechanism of Li et al. (- -) [40] and Burke et al. ( . .) [41].

$1 \mathrm{~mol} \%$ of the experimental data at $25 \mathrm{~mm}$ and $40 \mathrm{~mm}$ downstream. A comparison between the two computational results shows the effect of variational optimisation of the transition state, the lower reaction rates obtained using the variational approach clearly suppress gasphase ignition.

An agreement within $0.5 \mathrm{~mol} \%$ of experimental data is obtained for $\mathrm{CO}$ consumption in cases with $\mathrm{CO}_{2}$ dilution at all downstream locations (see Fig. 9). The conversion of $\mathrm{H}_{2}$ is under-predicted, while the mechanism of Vincent ea [7] (-) predicts conversion correctly. Results of rich syngas combustion are presented in Fig. 10. Consumption of $\mathrm{O}_{2}$ is well predicted in both cases. However, other experimental data are not well reproduced. The mechanism of Vincent et al. [7] shows no conversion. The overall trends - overprediction of $\mathrm{H}_{2}$ to $\mathrm{H}_{2} \mathrm{O}$ conversion and an underprediction of $\mathrm{CO}$ to $\mathrm{CO}_{2}$ conversion - are consistent with the findings of Schultze et al. [36] using the original mechanism of Deutschmann et al. [13].

A sensitivity analysis shows that agreement can be improved by enhancing the $\mathrm{CO}$ adsorption rate. After substituting the current $\mathrm{CO}$ adsorption rate (cf. R4 in Table 4) 


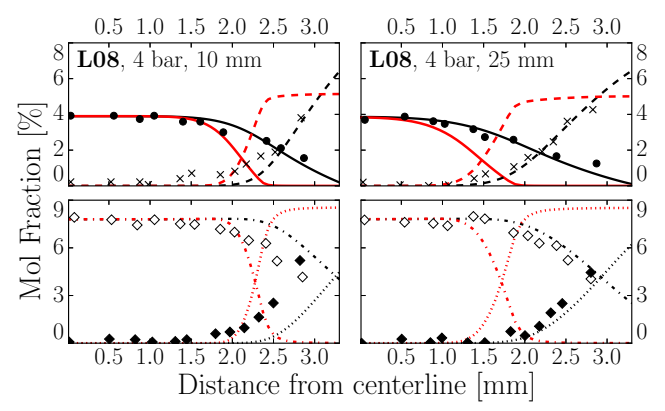

Figure 8: Experimental (symbols) and computational (lines) mol fraction profiles for $\mathrm{H}_{2}(\bullet,-), \mathrm{H}_{2} \mathrm{O}(\times,--)$, $\mathrm{CO}(\diamond,-\cdot)$ and $\mathrm{CO}_{2}(\diamond, \cdots)$ at two axial locations for the lean syngas case L08 [36]. Simulations with current mechanism based on VTST (-), and PES-shape TS determination (-).

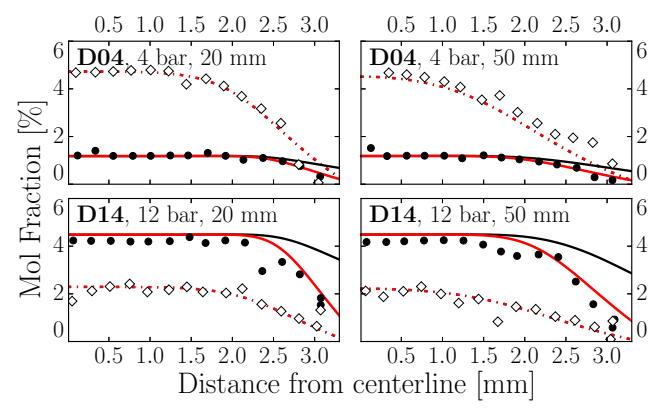

Figure 9: Experimental (symbols) and computational (lines) mol fraction profiles for $\mathrm{H}_{2}(\bullet,-)$ ) and $\mathrm{CO}$ $(\diamond,-\cdot)$ at two axial locations for the lean, $\mathrm{CO}_{2}$ diluted syngas cases D04 and D14 [37]. Simulations with current mechanism (-) and mechanism of Vincent et al. [7] (-).

with that proposed by Vincent et al. $\left(k=5.27 \times 10^{7} \times T^{0.5} \mathrm{~m} / \mathrm{s}\right)[7]$, the $\mathrm{H}_{2}$ consumption in Fig. 9 matches the results obtained with the full mechanism of Vincent et al. [7] exactly. The effect on rich syngas combustion is even more profound, as shown by (-) in Fig. 10, emphasising the complications with systematic treatment of $\mathrm{Pt}-\mathrm{CO}$ interaction $[17,53]$. A surface analysis (Fig. 6) shows that $\mathrm{H}(\mathrm{s})$ and $\mathrm{CO}(\mathrm{s})_{2}$ are adsorbed on approximately 1 and $10 \%$ of sites respectively, while the inlet molar ratio of $\mathrm{H}_{2}: \mathrm{CO}$ is $5: 1$, confirming a large preference for $\mathrm{CO}$ adsorption on $\mathrm{Pt}$ [54]. On the contrary, $\mathrm{CO}_{2}$ adsorption (R5) is not a sensitive parameter, as $\mathrm{CO}_{2}(s)_{2}$ desorption occurs readily. The site coverage results confirm the importance of studying reactivity of pre-covered surfaces [6], especially under lean conditions, with high surface oxygen coverages (R6/R7 in Table 4) [18, 53, 55]. 


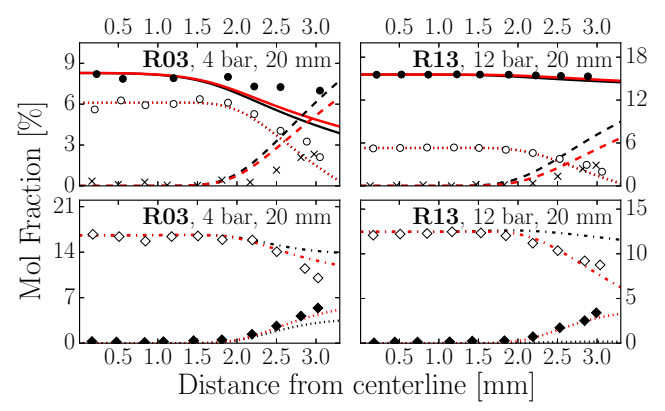

Figure 10: Experimental (symbols) and computational (lines) mol fraction profiles for $\mathrm{H}_{2}(\bullet,-), \mathrm{H}_{2} \mathrm{O}(\times,--)$, $\mathrm{O}_{2}(\diamond, \cdots), \mathrm{CO}(\diamond,-\cdot)$ and $\mathrm{CO}_{2}(\diamond, \cdots)$ at $20 \mathrm{~mm}$ downstream for rich syngas cases R03 and R13 [38]. $\mathrm{H}_{2}$ values scaled down by a factor of 4 for case R13. Simulations with current mechanism (-), and with CO adsorption rate of Vincent et al. [7] (-).

\section{Conclusion}

A theoretical class-based framework for the development of heterogeneous reaction mechanisms has been successfully applied and validated for the combustion of $\mathrm{H}_{2} / \mathrm{O}_{2} / \mathrm{N}_{2}$ and $\mathrm{CO} / \mathrm{CO}_{2} / \mathrm{H}_{2} / \mathrm{O}_{2} / \mathrm{N}_{2}$ mixtures over Pt. Experimental $\mathrm{H}_{2} / \mathrm{O}_{2}$ conversion and $\mathrm{H}_{2} \mathrm{O}$ production are well predicted, especially under rich conditions. The present mechanism shows excellent agreement for lean syngas combustion, highlighting the benefits of variational optimisation of the TS. The CO adsorption rate has been identified as a key parameter for lean cases with $\mathrm{CO}_{2}$ dilution, and in rich syngas combustion. Surface site analysis highlights the importance of adsorption processes on pre-covered surfaces, such as $\mathrm{O}(\mathrm{s})$ under lean conditions. The developed method reproduces experimental data without the reliance on experimental sticking coefficients and facilitates the efficient generation of novel heterogeneous reaction mechanisms.

\section{Acknowledgements}

R. P. Lindstedt and P. Kraus would like to thank Dr. I. Sakata and Dr. K. Gkagkas of Toyota Motor Europe for supporting this work; Dr. J. Mantzaras of Paul Scherrer Institute for sharing his experimental data and associated discussions; and Dr. T. Nagy and Dr. G. Lendvay for helpful tips and discussions during ECM 2015. 


\section{References}

[1] O. Deutschmann, S. Tischer, C. Correa, D. Chatterjee, S. Kleditzsch, V. M. Janardhanan, N. Mladenov, H. D. Minh, H. Karadeniz, M. Hettel, DETCHEM Software package (2014), URL: http://www.detchem.com.

[2] M. E. Coltrin, R. J. Kee, F. M. Rupley, Int. J. Chem. Kinet. 23 (12) (1991) 1111-1128.

[3] D. G. Goodwin, H. K. Moffat, R. L. Speth, Cantera: An Object-oriented Software Toolkit for Chemical Kinetics, Thermodynamics, and Transport Processes (2015), URL: http://www.cantera.org.

[4] Y. Chen, D. G. Vlachos, J. Phys. Chem. C 114 (11) (2010) 4973-4982.

[5] M. Salciccioli, Y. Chen, D. G. Vlachos, Ind. Eng. Chem. Res. 50 (1) (2011) 28-40.

[6] P. Raybaud, C. Chizallet, C. Mager-Maury, M. Digne, H. Toulhoat, P. Sautet, J. Catal. 308 (2013) 328-340.

[7] R. Vincent, R. P. Lindstedt, N. Malik, I. Reid, B. Messenger, J. Catal. 260 (1) (2008) 37-64.

[8] J. Warnatz, M. D. Allendorf, R. J. Kee, M. E. Coltrin, Combust. Flame 96 (4) (1994) 393-406.

[9] J. Ludwig, D. Vlachos, A. Van Duin, W. Goddard, J. Phys. Chem. B 110 (9) (2006) 4274-4282.

[10] D. K. Zerkle, M. D. Allendorf, M. Wolf, O. Deutschmann, J. Catal. 196 (2000) 18-39.

[11] J. E. Sutton, P. Panagiotopoulou, X. E. Verykios, D. G. Vlachos, J. Phys. Chem. C 117 (9) (2013) 4691-4706.

[12] N. R. Peela, J. E. Sutton, I. C. Lee, D. G. Vlachos, Ind. Eng. Chem. Res. 53 (24) (2014) 10051-10058.

[13] O. Deutschmann, R. Schmidt, F. Behrendt, J. Warnatz, J. Warnat, Proc. Combust. Inst. 26 (1) (1996) 1747-1754.

[14] B. Hellsing, B. Kasemo, S. Ljungström, A. Rosén, T. Wahnström, Surf. Sci. 189190 (0) (1987) 851-860.

[15] P. Kraus, R. P. Lindstedt, in: Proc. Eur. Combust. Meeting 2015, Budapest, 2015, pp. 2-5, URL: http://www.ecm2015.hu/papers/P5-61.pdf.

[16] P. Kraus, R. P. Lindstedt, in: Fifteenth Int. Conf. Numer. Combust., Avignon, 2015, p. 82, URL: http://www.nc15.ecp.fr/files/content/sites/nc15/files/Proceedings_web.pdf.

[17] E. Shustorovich, H. Sellers, Surf. Sci. Rep. 31 (1-3) (1998) 5-119.

[18] P. Kraus, R. P. Lindstedt, in: 9th Int. Conf. Chem. Kinet., 2015, pp. 376-379, URL: https://www.eiseverywhere.com/docs/3182/102181.

[19] R. S. Vincent, R. P. Lindstedt, N. A. Malik, I. A. B. Reid, B. E. Messenger, Proc. Combust. Inst. 33 (2) (2011) 1809-1817.

[20] W. R. Williams, C. M. Marks, L. D. Schmidt, J. Phys. Chem. 96 (1992) 5922-5931.

[21] M. Rinnemo, O. Deutschmann, F. Behrendt, B. Kasemo, Combust. Flame 111 (4) (1997) 312-326.

[22] H. Ikeda, J. Sato, F. Williams, Surf. Sci. 326 (1995) 11-26.

[23] N. Khadiya, N. Glumac, Combust. Sci. Technol. 159 (1) (2000) 147-168. 
[24] Norton, Wetzel, Vlachos, Ind. Eng. Chem. Res. 43 (16) (2004) 4833-4840.

[25] M. Sad, H. Duarte, C. Vignatti, C. Padró, C. Apesteguía, Int. J. Hydrogen Energy 40 (18) (2015) 6097-6106.

[26] Y. Liu, A. Lawal, Energy Technol. 2 (9-10) (2014) 792-801.

[27] F. Pompeo, G. Santori, N. N. Nichio, Int. J. Hydrogen Energy 35 (17) (2010) 8912-8920.

[28] R. Horn, K. a. Williams, N. J. Degenstein, a. Bitsch-Larsen, D. Dalle Nogare, S. a. Tupy, L. D. Schmidt, J. Catal. 249 (2) (2007) 380-393.

[29] R. W. Carr, Modeling of Chemical Reactions, Vol. 42, p. 89, Elsevier, 2007, ISBN: 9780444513663.

[30] J. Sabin, E. Brandas, Advances in Quantum Chemistry, Vol. 55, p. 51, Elsevier, 2008, ISBN: 9780123743350

[31] R. López-Fonseca, C. Jiménez-González, B. de Rivas, J. I. Gutiérrez-Ortiz, Appl. Catal. A Gen. 437-438 (2012) 53-62.

[32] J. A. Ruiz, F. B. Passos, J. M. Bueno, E. F. Souza-Aguiar, L. V. Mattos, F. B. Noronha, Appl. Catal. A Gen. 334 (1-2) (2008) 259-267.

[33] J. Mantzaras, R. Bombach, R. Schaeren, Proc. Combust. Inst. 32 (2) (2009) 1937-1945.

[34] Y. Ghermay, J. Mantzaras, R. Bombach, K. Boulouchos, Combust. Flame 158 (8) (2011) 1491-1506.

[35] M. Schultze, J. Mantzaras, R. Bombach, K. Boulouchos, Proc. Combust. Inst. 34 (2) (2013) 2269-2277.

[36] Y. Ghermay, J. Mantzaras, R. Bombach, Proc. Combust. Inst. 33 (2) (2011) 1827-1835.

[37] X. Zheng, J. Mantzaras, R. Bombach, Combust. Flame 160 (1) (2013) 155-169.

[38] M. Schultze, J. Mantzaras, F. Grygier, R. Bombach, Proc. Combust. Inst. 35 (2) (2014) 2223-2231.

[39] K. Leung, R. P. Lindstedt, Combust. Flame 102 (1-2) (1995) 129-160.

[40] J. Li, Z. Zhao, A. Kazakov, F. L. Dryer, Int. J. Chem. Kinet. 36 (10) (2004) 566-575.

[41] M. P. Burke, M. Chaos, Y. Ju, F. L. Dryer, S. J. Klippenstein, Int. J. Chem. Kinet. 44 (7) (2012) $444-474$.

[42] J. A. Dumesic, The Microkinetics of heterogeneous catalysis, ACS professional reference book, American Chemical Society, 1993, ISBN: 0841222142.

[43] B. C. Taverner, J. Comput. Chem. 17 (14) (1996) 1612-1623.

[44] J. W. Ochterski, Thermochemistry in Gaussian (2000), Gaussian Whitepaper, URL: http://www.gaussian.com/g_whitepap/thermo.htm.

[45] M. J. Frisch, G. W. Trucks, H. B. Schlegel, G. E. Scuseria, M. A. Robb, J. R. Cheeseman, G. Scalmani, V. Barone, B. Mennucci, G. A. Petersson, H. Nakatsuji, M. Caricato, X. Li, H. P. Hratchian, A. F. Izmaylov, J. Bloino, G. Zheng, J. L. Sonnenberg, M. Hada, M. Ehara, K. Toyota, R. Fukuda, J. Hasegawa, M. Ishida, T. Nakajima, Y. Honda, O. Kitao, H. Nakai, T. Vreven, J. A. Montgomery Jr., J. E. Peralta, F. Ogliaro, M. Bearpark, J. J. Heyd, E. Brothers, K. N. Kudin, V. N. Staroverov, R. Kobayashi, J. Nor- 
mand, K. Raghavachari, A. Rendell, J. C. Burant, S. S. Iyengar, J. Tomasi, M. Cossi, N. Rega, J. M. Millam, M. Klene, J. E. Knox, J. B. Cross, V. Bakken, C. Adamo, J. Jaramillo, R. Gomperts, R. E. Stratmann, O. Yazyev, A. J. Austin, R. Cammi, C. Pomelli, J. W. Ochterski, R. L. Martin, K. Morokuma, V. G. Zakrzewski, G. A. Voth, P. Salvador, J. J. Dannenberg, S. Dapprich, A. D. Daniels, Ö. Farkas, J. B. Foresman, J. V. Ortiz, J. Cioslowski, D. J. Fox, Gaussian 09 Revision D.01 (2009).

[46] Y. Zhao, D. G. Truhlar, Theor. Chem. Acc. 120 (1-3) (2008) 215-241.

[47] D. Andrae, U. Häußermann, M. Dolg, H. Stoll, H. Preuß, Theor. Chim. Acta 77 (2) (1990) 123-141.

[48] W. L. Hase, Acc. Chem. Res. 16 (4) (1983) 258-264.

[49] A. Isaacson, S. Rai, G. Hancock, Computer Phys. Comm. 41 (1987) 91-102.

[50] R. K. Robinson, R. P. Lindstedt, Combust. Flame 160 (12) (2013) 2642-2653.

[51] K. S. Pitzer, W. D. Gwinn, J. Chem. Phys. 10 (7) (1942) 428-440.

[52] J. Mantzaras, C. Appel, P. Benz, Combustion 28 (2000) 1349-1357.

[53] M. Happel, J. Mysliveček, V. Johánek, F. Dvorák, O. Stetsovych, Y. Lykhach, V. Matolín, J. Libuda, J. Catal. 289 (2012) 118-126.

[54] X. Feng, M. Yao, X. Hu, G. Hu, A. Jia, G. Xie, J. Lu, M. Luo, Int. J. Hydrogen Energy 38 (31) (2013) 13673-13679.

[55] X. Weng, H. Ren, M. Chen, H. Wan, ACS Catal. 4 (8) (2014) 2598-2604. 


\section{List of Tables}

1 Experimental conditions for hydrogen combustion studies in lean [33], preheated lean [34] and rich [35] cases: reactor length L, equivalence ratio $\phi$, $\mathrm{N}_{2} / \mathrm{O}_{2}$ molar ratio, superficial inlet velocity $\mathrm{U}_{i n}$, temperature of inlet gas $\mathrm{T}_{\text {in }}$, temperature of the catalytic wall at inlet $\mathrm{T}_{i n}^{W}$, pressure $\mathrm{P} . \quad \ldots \ldots$. . . . 3

2 Experimental conditions for syngas combustion studies in lean $(\phi=0.33)$ [36], $\mathrm{CO}_{2}$ diluted $(\phi=0.20)$ [37] and rich $(\phi=2$ and 7) [38] cases: inlet composition (balance is $\mathrm{N}_{2}$ ), superficial inlet velocity $\mathrm{U}_{i n}$, temperature of inlet gas $\mathrm{T}_{i n}$, temperature of the catalytic wall at inlet $\mathrm{T}_{i n}^{W}$, pressure $\mathrm{P} . \ldots . . . .3$

3 Formulas for determination of pre-exponential factors for all considered reac-

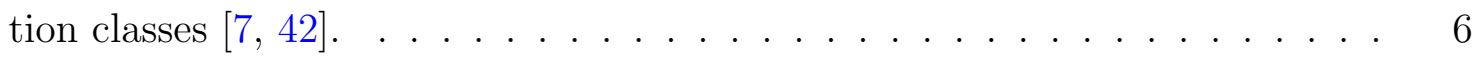

4 Selected reaction rate constants. . . . . . . . . . . . . . . . . 10 


\section{List of Figures}

1 A diagram of the computational domain overlaid over the outline of the experimental configuration. . . . . . . . . . . . . . . . 4

2 Transition state determination using canonical variational criterion $(-)$ and the PES-shape method (- -) for $\mathrm{H}_{2} \mathrm{O}$ and $\mathrm{COH}$ adsorption. Shaded lines indicate lack of an imaginary frequency. Structures on the left correspond to the adsorbed state, structures on the right correspond to a $0.6 \AA$ increase in bond length. . . . . . . . . . . . . . . . . . . . 7

3 Experimental (symbols) and computational (lines) mol fraction profiles for $\mathrm{H}_{2}$ $(\bullet,-)$ and $\mathrm{H}_{2} \mathrm{O}(\times,--)$ at two axial locations for lean $(\mathrm{L} 1, \mathrm{~L} 4, \mathrm{~L} 5)$ hydrogen combustion [33]. Simulations with gas and surface chemistry $(-)$, and with gas phase chemistry only $(-) \ldots \ldots \ldots \ldots$

4 Experimental and computational mol fraction profiles at two axial locations for the lean preheated (P07, P21) hydrogen combustion [34]. Symbols and lines as in Fig. 3. . . . . . . . . . . . . . . . . . . . . . 9

5 Experimental (symbols) and computational (lines) mol fraction profiles for $\mathrm{H}_{2}$ $(\bullet,-), \mathrm{H}_{2} \mathrm{O}(\times,--)$ and $\mathrm{O}_{2}(\circ, \cdots)$ at two axial locations for the rich hydrogen combustion cases R08 and R10 [35]. All $\mathrm{H}_{2}$ data is scaled down by a factor of 3 and 5 for cases R08 and R10 respectively. Simulations carried out with gas and surface chemistry. . . . . . . . . . . . . . . . . . 9

$6 \quad$ Stacked plot of site coverage of selected surface species at the catalytic wall in $\mathrm{H}_{2}$ and syngas combustion under fuel lean and rich conditions. . . . . . . 11

7 Homogeneous ignition distances for hydrogen combustion at $\phi=4.0$ [35]. Symbols $(+)$ represent experimental data, lines represent computational results obtained with surface chemistry and with the original gas-phase mechanism (-), mechanism of Li et al. (- -) [40] and Burke et al. ( . .) [41]. . . . 
8 Experimental (symbols) and computational (lines) mol fraction profiles for $\mathrm{H}_{2}(\bullet,-),, \mathrm{H}_{2} \mathrm{O}(\times,--), \mathrm{CO}(\diamond,-\cdot)$ and $\mathrm{CO}_{2}(\bullet, \cdots)$ at two axial locations for the lean syngas case L08 [36]. Simulations with current mechanism based on VTST (-), and PES-shape TS determination $(-) \ldots \ldots \ldots \ldots$

9 Experimental (symbols) and computational (lines) mol fraction profiles for $\mathrm{H}_{2}(\bullet,-)$ and $\mathrm{CO}(\diamond,-\cdot)$ at two axial locations for the lean, $\mathrm{CO}_{2}$ diluted syngas cases D04 and D14 [37]. Simulations with current mechanism (-) and mechanism of Vincent et al. [7] (-) . . . . . . . . . . . . . . . . . 12

10 Experimental (symbols) and computational (lines) mol fraction profiles for $\mathrm{H}_{2}(\bullet,-), \mathrm{H}_{2} \mathrm{O}(\times,--), \mathrm{O}_{2}(\circ, \cdots), \mathrm{CO}(\diamond,-\cdot)$ and $\mathrm{CO}_{2}(\bullet, \cdots)$ at $20 \mathrm{~mm}$ downstream for rich syngas cases $\mathrm{R} 03$ and $\mathrm{R} 13$ [38]. $\mathrm{H}_{2}$ values scaled down by a factor of 4 for case R13. Simulations with current mechanism $(-)$, and with CO adsorption rate of Vincent et al. [7] $(-) \ldots \ldots \ldots$. . . . . . . . . 13 
List of Supplementary Files

SMM/chem.inp:

Surface reaction mechanism and thermodynamic polynomials,

342 featuring 35 adsorbed species and 284 reversible reactions.

SMM/species.data.txt: Gas and surface species data used to calculate rate parameters, including bond energies and heats of adsorption. 